\title{
Literatura y política: dilemas culturales en Radiografía de la Pampa de Ezequiel Martínez Estrada
}

\author{
Adriana LAMOSO \\ Universidad Nacional del Sur
}

\begin{abstract}
RESUMEN
Si bien se reconoce que en los años treinta en Argentina el proceso de profesionalización del escritor se consolida a partir de la diferenciación de sus prácticas y de la visibilidad de su figura legitimada en la esfera cultural del país, el ensayista Ezequiel Martínez Estrada presenta una imagen de sí y de los intelectuales de la época que disputa con la postura hegemónica y establece un proyecto ideológico y estético que, despojado de incertidumbres, cuestiona y problematiza las estrategias del poder público, en quienes concentra la completa intensidad de su discurso denuncialista. Intelectuales y política se construyen en un contrapunto biunívoco y homogéneo, en tanto que resultan inescindibles y condenables. La confrontación con el aparato cultural, que se suscita en función de tales vínculos, desestabiliza la estandarizada imagen pública, referida a la autonomización relativa pero creciente de la cultura nacional. En este sentido, el trabajo consistirá en poner en tensión estas posiciones para traslucir las controvertidas circunstancias que diseña el ensayista respecto de su ubicación variable en el campo cultural local.
\end{abstract}

Palabras clave: ensayos, Martínez Estrada, intelectuales, campo cultural, Argentina.

\section{Literature and Politics: Cultural Dilemmas in Radiografía de la Pampa by Ezequiel Martínez Estrada}

\begin{abstract}
Even though it is well known that in the 30s in Argentina the process of professionalization of the writer gets consolidated due to the difference in their practices and the view of their legitimate figure in the cultural sphere of the country, the essayist Ezequiel Martínez Estrada presents an image of himself and the intellectuals of his time that disagrees with the hegemonic stance and establishes an ideological and aesthetic project that, divested of uncertainty, questions and causes problems to the strategies of the public power, in which concentrates the complete intensity of his denouncing speech. Intellectuals and politics are built in a biunivocous and homogeneous counterpoint, since they are not scissionable and condemnable. Struggle with the cultural system, which arouses due to such bonds, destabilizes the standardized public image, as regards the relative but growing act of becoming autonomous of our national culture. In this sense, the job will consist on straining these
\end{abstract}


positions to show the controversial circumstances that the essayist designs according to its changeable location in the local cultural field.

Keywords: essays, Martínez Estrada, intellectuals, cultural field, Argentina.

En la referencia al rol social que desempeñan los intelectuales en la década del '30 en Argentina, Ezequiel Martínez Estrada alude primariamente a un factor político como parámetro esencial de análisis y evaluación, en una época en la que los escritores registraron en sus producciones la desestabilización de imágenes que primaron por largo tiempo en el imaginario del país. En palabras de Oscar Terán: "[...] la creencia argentina en la excepcionalidad y el destino de grandeza de este país y en expectativas reales e imaginarias depositadas en la movilidad social ascendente" (Terán: 243).

No resulta sencillo reconstruir el horizonte de la vida cultural del país, sobre la base de las contundentes afirmaciones que realiza Martínez Estrada en su conocido ensayo de 1933, Radiografía de la pampa, ya que pone de relieve prácticas generalizadas, sistematizadas y compartidas por los agentes del poder público nacional con escritores, editores y lectores aunados en una praxis que homogeneiza a una totalidad. Tal imagen, que enlaza mecánicamente ambas esferas, sedimentada en el sentido común de la época, muestra su coincidencia con figuraciones recurrentes en escritores diversos, según ha sido reconocido ampliamente por la crítica ${ }^{1}$.

Frente al golpe de Estado de septiembre de 1930, la depresión económica, el fraude electoral y la represión de partidos políticos hegemónicos o de sectores gremiales contestatarios, y, en el ámbito internacional, ante los efectos de la Primera Guerra Mundial, el estalinismo y el fascismo europeos, el panorama literario que construye Martínez Estrada representa un escenario homogéneo y limitado a una dinámica lineal, mediante la cual la crisis material y moral del orden político se traduce en el dominio del ámbito de la cultura argentina, que reúne las mismas características.

${ }^{1}$ María Teresa Gramuglio apunta que "Lo primero exige reconocer la complejidad de los tiempos históricos, irreductibles a los esquemas simples de décadas y generaciones, puesto que en cualquier segmento que se recorte coexisten fenómenos de ritmo y duración desiguales: algunos nuevos o emergentes, otros ya asentados, que han alcanzado una colocación de predominio, otros que mantienen una presencia residual. Implica además admitir que no existe una sincronía absoluta entre los fenómenos político-sociales y la evolución de los procesos culturales y literarios. Desconociendo esos principios elementales, se han invocado algunas palabras recurrentes en los títulos de obras representativas de los años treinta como índice irrefutable del estado de desazón que habría invadido a los escritores a consecuencia de la situación política: "soledad", "silencio", "infamia". Los títulos: El hombre que está solo y espera (Raúl Scalabrini Ortiz), Historia universal de la infamia (Jorge Luis Borges), Hombres en soledad (Manuel Gálvez), La bahía de silencio (Eduardo Mallea), etc." (Los paréntesis me pertenecen) (Véase Gramuglio: 337). 
Sin intervenir activamente en la vida política del país, el ensayista sanciona a los intelectuales en virtud de que su desempeño opera de manera funcional con los espacios del poder oficial, para vehiculizar y reproducir las prácticas dominantes. Su construcción particular de los espacios culturales hace posible inferir que los debates de los escritores transitaron por caminos alejados de la discusión y problematización del aparato gubernamental y de su praxis; de este modo, el complejo y amplio espectro de posicionamientos, inflexiones, controversias y proyectos estéticoideológicos de la inteligencia, en torno a tales cuestiones, se ofrece en un borramiento altamente significativo, mientras que se sujetan a una dinámica que por sí misma diluye cualquier proyecto de intervención polémica.

En este sentido, es oportuno recordar que un sector importante de la intelectualidad argentina, frente a similar interpretación de la situación política, económica y social del país, ofreció diferente respuesta: la salida revolucionaria. A propósito de esto, resulta interesante aludir a las investigaciones de Sylvia Saítta, quien afirma:

El argumento del "peligro rojo", que como bandera de choque habían agitado los sectores nacionalistas, conservadores y católicos para reprimir huelgas, prohibir manifestaciones y detener a dirigentes gremiales o políticos, no era novedoso. Pero en los tempranos años treinta, motivando alarmas o suscitando adhesiones, ciertos procesos sociales parecían confirmar la proximidad de alguna profunda conmoción social. A Elías Castelnuovo, José Portogalo, Roberto Arlt, los hermanos Raúl y Enrique González Tuñón, entre otros muchos escritores, poetas y periodistas, el encuentro con la Rusia de los soviets y con el Octubre Rojo de Asturias de 1934, les permitió - como señala Beatriz Sarlo- diferenciarse del resto del campo cultural pues el impacto ideológico-político de la revolución se convirtió en el eje de sus discursos y de sus prácticas artísticas. Estos escritores de izquierda, que registraron la decadencia y la crisis, encontraron en ellas mismas una promesa de salida: la utopía revolucionaria. Esa promesa fue la instauración de un nuevo país cuyo modelo era la Rusia de los soviets primero, la República española después. (Saítta, 2001: 387)

Ante el horizonte ideológico y fáctico que se desprende de los escritores de izquierda, Martínez Estrada manifiesta su descontento y escepticismo político a través de la denuncia y condena de las prácticas de los intelectuales que reconoce sumidas en dos grandes líneas: las que actúan como soporte del Estado totalitario y las que se apartan para sucumbir irremediablemente. Del siguiente modo lee Martínez Estrada la posición que ocupa el sector de la inteligencia de Argentina, que se diferencia por oposición de los grupos nacionalistas, conservadores y católicos, ante los que el ensayista se (auto)construye al margen:

La vocación del artista y del sabio es un contrasentido con la realidad profunda, y el crítico que pasa en silencio las obras de enjundia y trompetea alrededor de las mistificaciones, está inconcientemente al servicio de las fuerzas oscuras de la pampa. Sobre los que se mantienen en pie trepa la hiedra de los que han fracasado 
hasta que los cubre como el pasto. Los muertos matan a los vivos, como en el palacio de los Atridas. (Martínez Estrada, 1993: 180)

Sobre el activismo político yace la condena del condicionante telúrico que los abraza, arrasa y los conduce hacia el fracaso; y la mano ejecutora de este factor ontológico se encuentra encarnada en la figura del político, quien completa aquel programa devastador. Esta interpretación contribuye a delinear la ubicación del ensayista en el campo intelectual nacional, a la vez que pone de manifiesto la construcción que elabora de sí mismo como un intelectual solitario, con una colocación marginal, al apartarse y distanciarse de los grupos que, desde el ámbito de la cultura, coincidieron en articular núcleos a partir de discursos, prácticas artísticas y nuevos modelos de intervención política compartidos. La palabra eficaz y el uso retórico de un lenguaje articulado, revelador y denuncialista constituyeron las armas de combate que consideró propicias para legitimar en la esfera pública tanto su propio lugar como escritor e intérprete, así como los mecanismos de indagación y dilucidación adecuados a las demandas de sentido socialmente existentes. Se sabe que un amigo del ensayista, el editor Samuel Glusberg, propició la escritura de Radiografia, a la luz de las inquietudes insatisfechas de los lectores de la época, y de este modo, actuó como un propiciador cultural antes que como mero editor ${ }^{2}$.

Como ha hecho referencia la crítica, en la década del '20, Martínez Estrada junto a Horacio Quiroga, Luis Franco, Samuel Glusberg, editor de las publicaciones de los miembros del grupo bajo el sello Babel y narrador que firmaba con el seudónimo de Enrique Espinoza, con la tutela de Leopoldo Lugones, conformaron un núcleo singular, una suerte de fraternidad intelectual, que se reunía en cafés y bares del centro porteño, así como en la biblioteca del Consejo Nacional de Educación, cuyo Director era Lugones, cargo burocrático que ocupó desde 1915 hasta su muerte en 1938. Si tenemos presente la 'hermandad' (Tarcus: 15) y consideramos, además, que este escritor publicó numerosos artículos en el diario La Nación desde 1927, materiales que editó en el libro La patria fuerte en 1931, y que estos textos fueron soporte del consenso que haría posible la caída del gobierno de Yrigoyen y facilitaría las vías para que el golpe de Estado de Uriburu tuviera lugar, hechos que, por otra parte, provocaron la virulenta reacción de vastos sectores de la inteligencia del país, resulta altamente complejo trazar un mapa de confluencias y oposiciones en la cultura argentina a partir de la lectura enjuiciadora presente en Radiografía de la Pampa. Recordemos la fuerte estocada que el ensayista profiere a los escritores nacionales que se vinculaban con las empresas periodísticas y con las instituciones del Estado, en virtud de que conducían por camino directo al sistema político vigente y a sus prácticas. Pero es también desde las páginas del mismo diario que Lugones manifestó su reconocimiento al propio Martínez Estrada, mediante la reseña en la que lo denominó "Laureado del gay mester" en 1929, artículo que contribuyó, en gran parte,

\footnotetext{
${ }^{2}$ Cfr. Saítta, 2004: 109.
} 
a consolidar su legitimidad cultural en el marco de las prácticas de la inteligencia argentina.

Horacio Tarcus registra, a partir del intercambio epistolar entre los miembros del grupo, que, así como la década del '20 fue testigo de la reunión de la cofradía, la década del '30 presenció su diáspora. Los miembros de la hermandad, aún desde la heterogeneidad que particularizaba a cada uno de ellos, compartían posturas ideológicas, políticas y culturales, en algunos aspectos afines, como el distanciamiento de la tradición española, la sensibilidad laicista, anticlerical, el anticapitalismo, así como el espíritu libertario y antiburgués. Sin embargo, a partir del año de publicación de Radiografía, Martínez Estrada se replegaba, por primera pero no por última vez, de la vida pública y se instalaba en su chacra de Goyena. Así lo expresa en su ensayo El hermano Quiroga, escrito en 1956:

Hacia 1930, Quiroga escribía muy poco, pero aún no había madurado su aversión a hacerlo [...]. Yo había decidido no escribir más poesía, coronado de laureles de oro y amortajado de silencio por mis cofrades. Progresivamente, él y yo, llegamos a la certeza de que nuestra Campaña del Desierto había terminado.

Charlábamos de literatura, empero; y ése fue el tema central de nuestras charlas en el Hospital de Clínicas. "Más allá" fue su último libro, y yo había jurado no publicar más, después de la condenación unánime por la "intelligentsia" de mi "Radiografía de la pampa". Nuestro retiro en la selva misionera era dejarles las colas a los cazadores. (Martínez Estrada, 1968: 62)

La edición de Radiografía de la Pampa fue posible, como ya mencionamos, gracias al respaldo del sello Babel, proyecto cultural perteneciente a Glusberg, lo que contribuyó a marcar un centro de gravitación nuclear en cuanto a su rol de escritor nacional, máxime si consideramos que Martínez Estrada se sumó a las políticas culturales llevadas a cabo por el editor desde la publicación de Argentina en 1927, por parte de la nombrada editorial. Además, escribió artículos tanto para la revista Cuadernos literarios de Oriente y Occidente, como para La vida literaria, que correspondían a Glusberg y apoyó sus políticas culturales, por ejemplo, a través de su participación en la organización de la gira argentina de Waldo Frank y mediante su intervención para promover la instalación en el país de José Carlos Mariátegui.

Por su parte, si bien el éxito de ventas del ensayo no fue significativo (se produce una segunda edición recién en el año 1942), las controvertidas intervenciones críticas de intelectuales como Jorge Luis Borges con "Radiografía de la Pampa por Ezequiel Martínez Estrada", publicado en Crítica en septiembre de 1933, o Luis Emilio Soto, "Análisis espectral de la Pampa," y "Arbitraje espiritual", editados en Crítica y Estimación en 1938, así como el enjuiciador artículo de Bernardo Canal-Feijóo, titulado "Radiografías fatídicas" y publicado en $\operatorname{Sur}\left(\mathrm{n}^{\circ} 37\right)$, en octubre de 1937, entre otros, dieron cuenta del lugar crucial que Martínez Estrada ocupó en la vida cultural de la época, a lo que se sumaron las primeras reseñas que sobre su obra editaron en la revista Babel los autores Julio Finguerit y Ricardo Rojas, también se destacan los cargos y funciones que desempeñó (fue nombrado Presidente de la Sociedad Argentina de Escritores (SADE), entre 1933 y 1934), así como la prolífera 
publicación de artículos en diarios y en revistas reconocidas, como Anales del Instituto Popular de Conferencias, Boletín de la Universidad Nacional de La Plata, El Hogar, Sur, Nosotros, La Literatura Argentina, La Revue argentine (Paris) y Revista de la Sociedad de Escritores de Chile, para señalar sólo algunos nombres; y sobre todo la obtención en 1937 del Segundo Premio Nacional de Literatura por Radiografia de la Pampa.

El reclamo de autonomía respecto de las instancias de poder, implica, a pesar de la paradoja que significa la presencia del condicionante telúrico, no sólo una tenaz lucha por democratizar el acceso y la permanencia independiente en los órganos culturales del país, sino que también significa el deseo de consolidar la profesionalización del escritor argentino, que ya había iniciado su proceso desde principios de siglo, pero que si bien no carecía de vías y canales de participación, como por ejemplo la Sociedad Argentina de Escritores que fue fundada en 1928, la filial argentina del PEN CLUB, existente a partir de 1930 y la Academia Argentina de Letras, creada por el Gobierno Provisional de Uriburu en 1931, resultaba necesario establecer un programa y definir políticas para proteger los derechos de los autores, regular sus vinculaciones con el aparato gubernamental y cultural existentes, tendientes a obtener reconocimiento respecto de la función social que desempeñaban, delimitar y obtener vías que crearan las condiciones de posibilidad para procurar a los escritores medios de vida que fueran resultantes de su profesión, lo que se conecta con la regulación de sus relaciones con las editoriales. Recordemos que, a pesar de y junto con los premios literarios que recibió, su ocupación central consistió en desempeñarse como empleado público en el Correo Central de Buenos Aires, desde 1914 hasta su jubilación en 1946, y como 'Profesor de Literatura' en el Colegio Nacional dependiente de la Universidad Nacional de La Plata desde 1924 hasta 1945, año en el que renunció por su oposición al gobierno de Perón.

Si volvemos a retomar los cuestionamientos que Martínez Estrada profiere a la inteligencia nacional en su ensayo Radiografía de la Pampa, no podemos soslayar la alusión a los grupos, ideas y movimientos que repensaban críticamente el funcionamiento teórico y práctico del consenso liberal, que venía desarrollándose desde la década de 1920. Nos referimos a la creciente intervención de los militares en la esfera política, a la mayor movilización e incursión en los affaires políticos y sociales de la Iglesia Católica y a la emergencia de un multifacético nacionalismo en lo relativo a cuestiones políticas y culturales. En el ámbito literario, estos núcleos ideológicos encontraron eco, aunque con inflexiones variadas, en numerosos intelectuales del país, entre los que podemos mencionar a Leopoldo Lugones, Carlos Ibarguren, Manuel Gálvez, Raúl Scalabrini Ortiz, Delfina Bunge de Gálvez, y el grupo asociado a la revista nacionalista La Nueva República, que aglutinaba entre otros a Rodolfo y Julio Irazusta y a Ernesto Palacio ${ }^{3}$.

\footnotetext{
${ }^{3}$ Cfr. Nállim: 118 .
} 
La postura de Martínez Estrada respecto de los sectores que articularon sus discursos en pro del gobierno de facto, se ofrece mediante un recalcitrante enjuiciamiento condenatorio que se expresa del siguiente modo:

Simulacros de escritores, de artistas, de sabios han ocupado mediante la entrega condicional de su persona los altos puestos. Enseñoreados de los diarios, las cátedras y los cenáculos, defienden con uñas y dientes su empleo. Aquellos apóstatas que claudicaron en su fe son los apóstoles de ese ideal urbano, los herejes sublimados del contraideal. Diarios, universidades y salones se sostienen por un complejo sistema de intereses cruzados; unos amparan a los otros y a lo largo de los personajes encadenados circula una sola sangre y un solo fluido vital: la política [...]. Formas abortivas y monstruosas, nacidas de cópulas gubernamentales, engendradas con los logos espermáticos de la política, se multiplican por sí mismas en pululación de bacterias, en obras completas de treinta títulos. El Congreso vota fondos para que se escriban obras o para adquirirlas. Son fantasmas a la rústica. Las Plazas están llenas de simulacros de bronce y de mármol; los museos atestados de simulacros; los programas sinfónicos mechados de fantasmas. Todo ese mundo de los abortos inmortales nace de la política y es hijo de las cámaras, de los gabinetes y de los comités. El público está complicado en el sistema de la cadena y aplaude; llena los teatros y repite los gloriosos nombres de los espectros. (Martínez Estrada, 1993: 180-1)

La negativa evaluación que Martínez Estrada ofrece sobre el núcleo de escritores de derecha y sobre la coyuntura política en gestión arroja pistas que tornan factible inferir la concreción de su alejamiento de la élite intelectual argentina que lo había premiado, mientras se aparta paralela y explícitamente de la cultura oficial. En palabras de Liliana Weinberg: "[...] por esas fechas Lugones se convierte en el ideólogo del régimen encabezado por Uriburu y propugna la instauración de una sociedad corporativa cuyo destino sólo podría ser regido por una minoría selecta integrada por militares y artistas iluminados" (Weinberg de Magis: 476). En este contexto, su corrimiento del marco ideológico que propugnaba el apoyo al estilo de gobierno autoritario que la revolución había instaurado, conlleva el reconocimiento de su pertenencia a la clase media argentina, desplazada del poder a partir del derrocamiento del gobierno de Yrigoyen, la que se precipitó en una crisis profunda de valores que el ensayista reclama con urgencia restituir.

El escepticismo del ensayista, explícito en Radiografía de la Pampa, respecto de las condiciones de posibilidad para que una praxis político-intelectual resulte eficaz, condice, además, con su claudicación al proyecto del grupo MELT ${ }^{4}$, encabezado por

4 "Hacia 1932, Martínez Estrada, Luis Franco y Samuel Glusberg, una vez que dieron por concluido el ciclo de La vida literaria, resolvieron lanzar una nueva revista. Repolitizados por el clima que vivía el país tras el golpe militar de septiembre de 1930, los tres desplazaron sus ficciones literarias a un segundo plano para privilegiar un nuevo género: el ensayo de interpretación histórica, política y cultural [...]. Según se desprende de sus cartas, la revista no se limitaría a los temas culturales sino que asumiría una identidad política de izquierda. Los 
Franco y Glusbeg, retracción ante la cual se efectivizó la diáspora de la hermandad por varios años. Mientras Martínez Estrada descree del activismo de la inteligencia en el marco del pensamiento de izquierda, que pretendía vehiculizar la intervención antifascista en el país, comienza su paulatina vinculación con la fracción liberal de la revista Sur, y se llama al silencio respecto del rol político desempeñado por Lugones en esa época.

En la tarea que emprende se autoconfigura como un artista honesto y solitario, que no transige con el poder, por lo que constituye lo que él denomina 'un eslabón suelto', rasgo que, en el marco de sus razonamientos, lo predestina a sucumbir. Respecto de la suerte del escritor contemporáneo expresa: "Los mejores son pobres y viven de otra cosa. Persisten en su trabajo porque Dios lo quiere así" (Martínez Estrada, 1993: 181). Apela, de este modo, encubiertamente a los lectores, y los insta a apartarse del consumo masivo que el establisment impone, mediante poderosas empresas de prensa que responden al orden político nacional. Por eso, construirse al margen de estas dinámicas es la opción más propicia para inducir a la adhesión, a la vez que recuerda el pensamiento del sector liberal, en particular, el propulsado a principios del siglo XX por José María Ramos Mejía, quien presenta una visión altamente negativa de fenómenos propios de la modernidad, como los periódicos, y que se expresa a partir del repudio a la tarea desempeñada por el periodismo cultural del país, por tratarse de ejercicios que detentan el engaño y la sugestión. A esta posición acompaña la desconfianza en la ampliación del público lector, como consecuencia de la difusión de la enseñanza pública, núcleo idiosincrásico del proyecto liberal del siglo XIX, no por la efectiva posibilidad de adquisición de las habilidades pertinentes para tal tarea, sino debido a que considera al pueblo inmerso en un rol altamente pasivo e inferior; lo ve incapaz de 'leer' lo 'pertinente' y 'acertado'. Esta postura se vincula, a su vez, con la consigna propia de la corriente de optar por una 'república aristocrática' a partir de la cual, los que gobiernan se legitiman en su función por poseer 'mayor competencia' que las masas y, con ello, encarnan el deber moral de conducirlas según sus imperativos y mandatos, lo que conlleva la suspensión de la soberanía popular. Las ideas expuestas, situadas en el plano político de la línea liberal, conducen unívocamente al proyecto de autolegitimación como intelectual que construye el ensayista, ya que su (auto) configuración entrelaza al rol del gobernante con el que él mismo diseña sobre sí en tanto escritor nacional.

tres hermanos, buscando reunir un equipo editor, establecieron contactos con una serie de escritores, periodistas y traductores que se situaban en la izquierda opositora al comunismo oficial. Participaron del grupo inicial el filósofo Héctor Raurich, el periodista y traductor Carlos Liachovizty (que firmaba Carlos Liacho, o Tristán Suárez) y los médicos Héctor Meyer y Oscar Cohan, este último también traductor de Nietzsche y Spinoza. Tiempo después tomarán parte en las reuniones el joven ensayista Antonio Gallo, el periodista cordobés Luis Reinaudi y el escritor Octavio Rivas Rooney.

En las cartas de Martínez Estrada y Luis Franco aparecen reiteradas menciones a este grupo como "MELT" o como "grupo meltiano" [...]" (Tarcus: 57) 
A partir del desarrollo de las líneas que anteceden, es posible apreciar el lugar peculiar que Martínez Estrada delineó del campo intelectual argentino en los inicios de la década infame, así como las estrategias de autofiguración que colocan al ensayista en un espacio alejado de los núcleos más renombrados que aglutinaron las ideologías político-culturales del país, a las que construye desdibujadas en una generalidad excluyente de sus emergencias, variabilidades y redefiniciones. El ensayo articula una coyuntura política fuertemente impactante y desestabilizadora de las esperanzas puestas en el programa político-social del radicalismo de Yrigoyen, y manifiesta la virulenta condena al proyecto ideológico y fáctico del gobierno de los generales Uriburu y Justo. Las vinculaciones que enlazan el campo de poder con la esfera cultural reciben contundentes impugnaciones. El determinismo telúrico resulta un condicionante severo que incide en las prácticas configuradas como previsibles. La ubicación del escritor al margen del horizonte trazado instaura un espacio alternativo, sólo habitable por el intérprete solitario, que inaugura una nueva instancia de intervención con la que encubre una aspiración y un deseo, no exentos de la contradicción ni de la paradoja: el acceso a un público lector más amplio y el reconocimiento social de su legítima función.

\section{BIBLIOGRAFÍA}

CATTARUZZA, Alejandro (dir.).

2001 Nueva Historia Argentina, Crisis Económica, Avance del Estado e Incertidumbre Política (1930-1943). Tomo 7. Buenos Aires: Sudamericana.

GONZÁLEZ, Horacio.

2002 Retórica y locura. Para una teoría de la cultura argentina. Buenos Aires: Colihue.

GramugLio, María Teresa.

2001 "Posiciones, transformaciones y debates en la literatura", en Alejandro Cattaruzza (dir.). Nueva Historia Argentina, Crisis Económica, Avance del Estado e Incertidumbre Política (1930-1943). Tomo 7. Buenos Aires: Sudamericana.

HALPERIN DONGHI, Tulio.

2003 La Argentina y la tormenta del mundo. Ideas e ideologías entre 1930 y 1945. Buenos Aires: Siglo XXI Editores.

2004 La República imposible (1930-1945). Buenos Aires: Ariel. MARTÍNEZ ESTRADA, Ezequiel.

1968 El hermano Quiroga y cartas de Horacio Quiroga a Martínez Estrada. Montevideo: Arca.

1993 Radiografía de la Pampa. México: Consejo Nacional para la Cultura y las Artes, Colección Archivos. 
NÁLLIM, Jorge.

2003 "De los intereses gremiales a la lucha política: la Sociedad Argentina de Escritores (SADE), 1928-1946", Primas. Revista de Historia Intelectual, año $7, \mathrm{n}^{\mathrm{o}} 7$, Buenos Aires, Universidad Nacional de Quilmes.

NEIBURG, Federico y PlOTKIN, Mariano (comp.)

2004 Intelectuales y expertos. La constitución del conocimiento social en la Argentina. Buenos Aires: Paidós.

SAÍTTA, Sylvia.

2001 "Entre la cultura y la política: los escritores de izquierda", en Alejandro Cattaruzza (dir.). Nueva Historia Argentina, Crisis Económica, Avance del Estado e Incertidumbre Política (1930-1943). Tomo 7. Buenos Aires: Sudamericana.

2004 "Modos de pensar lo social. Ensayo y sociedad en la Argentina (1930-1965)", en Federico Neiburg y Mariano Plotkin (comp.). Intelectuales y expertos. La constitución del conocimiento social en

TARCUS, Horacio. la Argentina. Buenos Aires: Paidós.

2009 Cartas de una hermandad. Leopoldo Lugones, Horacio Quiroga, Ezequiel Martinez Estrada, Luis Franco, Samuel Glusberg. Buenos Aires: EMECE.

TERÁN, Oscar.

2009 Historia de las ideas en la Argentina. Diez lecciones iniciales, 18101980. Buenos Aires: Siglo XXI Editores.

WEINBERG DE MAGIS, Liliana.

1993 "Radiografía de la Pampa en clave paradójica", en Martínez Estrada, Ezequiel. Radiografía de la Pampa. México: Consejo Nacional para la Cultura y las Artes, Colección Archivos. 